\title{
Response to "Redundancy of terms is not an error but plays a positive role in composing search strategies"
}

\author{
Jose Antonio Salvador-Olivan; Gonzalo Marco-Cuenca; Rosario Arquero-Avilés
}

See end of article for authors' affiliations.

Response to Schoones J. Redundancy of terms is not an error but plays a positive role in composing search strategies [letter to the editor]. J Med Libr Assoc. 2020 Jan;108(1):118-9. DOI:

http://dx.doi.org/10.5195/jmla.2020.780.

Comment on Salvador-Oliván JA, Marco-Cuenca G, Arquero-Avilés R. Errors in search strategies used in systematic reviews and their effects on information retrieval. J Med Libr Assoc. 2019 Apr;107(2):210-21. DOI: http://dx.doi.org/10.5195/jmla.2019.567.

To the editor, we agree with Schoones [1] that redundant terms (and their morphological variants) are beneficial for search planning (i.e., search strategy composition), so it is advisable to consider all possible terms (and their morphological variants) that may be used to represent a concept.

We also agree that a search strategy is a "Livin' Thing" and that its results dictate whether the initial search strategy is also the final strategy. However, the search strategy published in a systematic review must be the final strategy that was executed in the databases and that produced the results indicated in the flowchart. It is this search strategy that enables a study to be replicated and that will be evaluated in the peer-review process. In our study, we assessed the published strategies, not the initial or intermediate strategies that were tested.

Authors justify redundancy because the decision to include or exclude terms depends on the references retrieved, as the effect of the terms on the results is impossible to predict. In the proposed example, with the search statement of "massive chronic intervillositis" [tw] OR "chronic intervillositis"[tw] OR "chronic histiocytic intervillositis"[tw] OR "histiocytic intervillositis"[tw]
OR "intervillositis"[tw], it is known beforehand that "intervillositis"[tw] will retrieve all records that contain this term (individually or as part of a sentence), so other terms are unnecessary.

Redundant terms in a search strategy do not affect the retrieval of information. The principle of parsimony instructs us to eliminate that which is unnecessary. Applied to information retrieval, this principle prompts us to eliminate any terms or phrases from a search strategy that do not retrieve or provide new records, as they are thus unnecessary.

\section{REFERENCE}

1. Schoones J. Redundancy of terms is not an error but plays a positive role in composing search strategies [letter to the editor]. J Med Libr Assoc. 2020 Jan;108(1):118-9. DOI: http://dx.doi.org/10.5195/jmla.2020.780.

\section{AUTHORS' AFFILIATIONS}

José Antonio Salvador-Oliván, MD, PhD, jaso@unizar.es, https://orcid.org/0000-0001-8568-3098, Professor, Department of Library and Information Science and Faculty of Medicine, University of Zaragoza, Zaragoza, Spain

Gonzalo Marco-Cuenca, gmarco@unizar.es, https://orcid.org/00000002-7149-6192, Professor, Department of Library and Information Science and Faculty of Medicine, University of Zaragoza, Zaragoza, Spain 
Rosario Arquero-Avilés, carquero@ucm.es, https://orcid.org/00000002-3097-8734, Professor, Department of Library and Information Science, Complutense University of Madrid, Madrid, Spain

Received September 2019; accepted September 2019

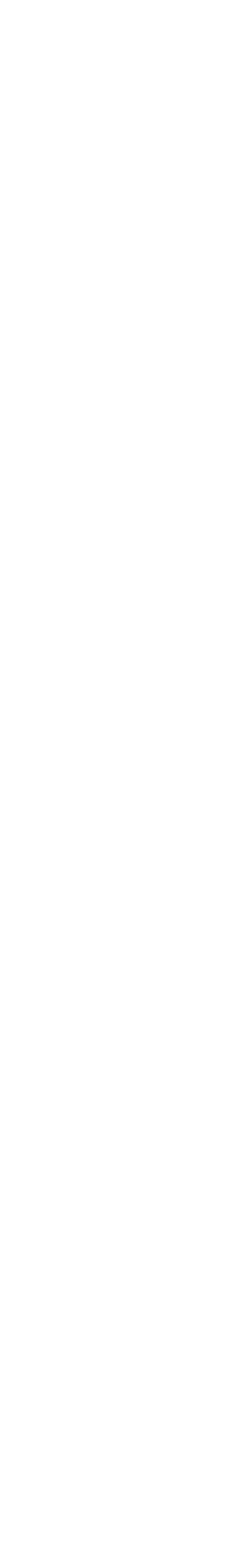

Articles in this journal are licensed under a Creative Commons Attribution 4.0 International License.

This journal is published by the University Library System

of the University of Pittsburgh as part of its D-Scribe

Digital Publishing Program and is cosponsored by the University of Pittsburgh Press. 